\title{
Outcome Evaluation of Zero-Profile Implant Compared with an Anterior Plate and Cage Used in Anterior Cervical Discectomy and Fusion: A Two-Year Follow-Up Study
}

\author{
Liang ZHANG, Jingcheng WANG, Yuping TAO, Xinmin FENG, Jiandong YANG, Shengfei ZHANG \\ Yangzhou University, Clinical Medical College, Yangzhou, China
}

\section{ABSTRACT}

AIM: To compare the clinical outcome and complications between Zero-P implant and cage with anterior plate in patients undergoing anterior cervical discectomy and fusion (ACDF).

MATERIAL and METHODS: 50 patients underwent ACDF operation of which 23 patients had Zero-P implanted and 27 had cage and plate implanted. Preoperative and Post-operative clinical evaluation included Japanese Orthopaedic Association (JOA) score, Neck Disability Index (NDI) score and Short form 36 (SF-36). Incidences of dysphagia-related symptoms were recorded. Plain radiographs were performed 2 days postoperatively and at follow-up to evaluate cervical prevertebral soft tissue, sagittal alignment, fusion rate and implant failure.

RESULTS: In both groups, the JOA and SF-36 scores significantly increased, cervical sagittal alignment significantly corrected and the NDI score dropped compared to the preoperative at follow-up. All patients achieved solid fusion and no implant displacement was observed. The thickness of the prevertebral soft tissue at 2 days and 3 months postoperatively was lower in the Zero-P group. The incidence of dysphagia in the Zero-P group was significantly lower and the duration was much shorter.

CONCLUSION: Zero-P used in ACDF could lead to similar clinical and radiographical outcomes compared with cage and plate, but with lower incidence and shorter duration of dysphagia.

KEYWORDS: ACDF, Plate, Zero-P, Dysphagia

\section{INTRODUCTION}

Since its introduction proposed by Smith and Robinson (1958) (21), anterior cervical discectomy and fusion (ACDF) has become the "gold standard" treatment of degenerative cervical disc disease (DCDD) for elderly patients or patients with contra-indications for disc prosthesis (10). Although the use of autologous iliac bone can provide solid fusion, the incidence of donor-site morbidity and complications including hematoma formation, pain, infection and neurological injury were still not negligible. To avoid these problems, varieties of cervical cages have been developed $(7,29)$. Considering that the stand-alone cages are associated with high incidences of implant subsidence, many surgeons prefer to add an anterior plate to enhance the stability to reduce graft-related complications and increase fusion rates $(11,24)$.

Although the profile of current plates is thinner than earlier designs, the plates are still bulky and may lead to increased risk of complications such as screw or plate dislodgement, soft-tissue damage and dysphagia especially in multilevel procedures $(4,30)$. An inappropriate sized or misaligned plate may affect the movement of the adjacent level and increase the risk of adjacent segment degeneration $(9,28)$. The incidence of early dysphagia after ACDF ranges from less than $4.0 \%$ to greater than $57.0 \%$, and $6.9 \%$ to $35.1 \%$ of patients' dysphagia persists for more than 3 months $(8,32)$. 
To avoid these complications, a new Zero-profile anterior cervical interbody fusion device, the Zero-P (Synthes GmbH Switzerland, Oberdorf, Switzerland), was developed and approved to use for patients with DCDD by the United States Food and Drug Administration in 2008. In this system, a designed plate with four angle-controlled screw trajectory, where screws could get into the vertebral body through the end plate, is attached to the front of the cage. The whole device can be implanted into the intervertebral space to avoid the implant contact to the front soft tissue of the cervical. It has been shown to provide similar biomechanical stability to that of fusion using cervical cage and plate constructs (18). Early results have shown neurological improvement and infrequent post-operative dysphagia $(14,19,30)$. In this study we compared the early clinical outcome and complications between Zero-P implant and cage with anterior plate in patients with DCDD undergoing ACDF.

\section{MATERIAL and METHODS}

Between May 2010 and May 2012, 50 selected patients (24 male, 26 female) who underwent ACDF were enrolled prospectively. All patients had cervical radicular symptoms or neurological deficits failing conservative treatment for at least 6 weeks. 23 patients with a mean age of 48.6 years (range 33-65 years) had a total of 27 Zero-P implanted. Another 27 patients, with a mean age of 52.7 (range 36-72 years), had a common cage implanted with an anterior titanium plate. The mean follow-up time ranged from 24 to 36 months (mean 28.5 months). Both groups were comparable regarding the characteristics of the patients. (Table I).

Preoperative anteroposterior (AP) and lateral radiographs, computed tomography $(\mathrm{CT})$ and magnetic resonance imaging (MRI) scans were obtained (Figures 1A-D; 2A-D; 3A-D). All patients underwent a right-sided Smith-Robinson approach. The Zero-P device contains a polyether ether ketone (PEEK) body with tantalum markers to control the position during insertion. Correct position of the Zero-P was controlled by using an image intensifier in lateral and AP views. The device should be placed $2 \mathrm{~mm}$ behind the anterior column in the lateral view and in the center of the disc space in the AP view (19). The anterior plate was Slim-Loc (Johnson \& Johnson Co., DePuy Spine Ltd., Raynham, Massachusetts). All patients wore a Philadelphia collar for one month post-operatively.

Preoperative and Post-operative clinical evaluation were done by a team comprising a neurologist, pain specialist and a neurosurgeon. This included the Japanese Orthopaedic Association (JOA) score for neurological function, Neck Disability Index (NDI) score for neck function and Short form 36 (SF-36) for the general quality of life. Incidence of dysphagiarelated symptoms were graded depending on the patient's state as none (no episodes of swallowing problems), mild (rare episodes of dysphagia), moderate (occasional swallowing difficulty with specific food), and severe (frequent difficult swallowing with majority of food) according to Bazaz et al. (2). Plain radiographs (AP and lateral views) were performed 2 days postop and at each follow up ( 3 months, 12 months, and 24 months). The predominant swelling of the prevertebral soft tissue was observed at the C3 level after ACDF operation, and thus the degree of cervical prevertebral soft tissue was measured as the distance between the anterior surface of C3 vertebral body and the air shadow of the airway $(22,26)$. In the area where the plate was fixed, the distances from the anterior margins of the plates to a shadow were measured. The Cobb angle, measured as the acute angle constructed by the lines going along the back of $\mathrm{C} 2$ and $\mathrm{C} 7$ vertebral body on the standing lateral cervical X-ray, was used to evaluate the sagittal alignment of the cervical spine (16).

Data were analyzed using SPSS 16.0. The paired t-test was used to assess the difference of aimed outcomes before and after operation. Pearson Chi-Square $\mathrm{c}^{2}$ test was used to assess the difference in dysphagia rates. A p-value of $<0.05$ was considered significant.

\section{RESULTS}

The JOA and SF-36 scores significantly increased and the NDI score dropped compared to the preoperative values at followup time $(p<0.05)$, but without significant differences during the follow-up period in both groups ( $p>0.05$ ) (Table II).

All patients achieved solid fusion and no implant displacement was observed at final follow-up in both groups (Figure 4A-D; $5 A-D ; 6 A-D)$. The cervical sagittal alignment had a significant correction (from $9.4^{\circ}$ to $13.8^{\circ}$ in Zero-P group $(p<0.05)$ and from $10.1^{\circ}$ to $14.8^{\circ}$ in the cage with plate group $\left.(p<0.05)\right)$ and was maintained well (Table III). The thickness of the prevertebral soft tissue at 2 days and 3 months postoperatively was significantly lower in the Zero-P group than that in the cage with plate group $(p<0.05)$, but without significant differences at 12 and 24 months follow-up ( $p>0.05$ ) (Table III).

In the Zero-P group, 5 of 23 patients (21.7\%) had transient postoperative mild dysphagia ( $<3$ months) and only 1 patient

Table I: Patient Characteristics of Study Groups

\begin{tabular}{lccc}
\hline & Zero-P & Cage with plate & $\mathbf{p}$ \\
\hline Sex & & & \\
\hline Male & 11 & 13 & $>0.05$ \\
\hline Female & 12 & 14 & \\
\hline Age (yr) & $33-65$ & $36-72$ & \\
\hline Mean & $48.6 \pm 8.1$ & $52.7 \pm 8.3$ & $>0.05$ \\
\hline Number of treated segments & & \\
\hline One & 19 & 21 & $>0.05$ \\
\hline Two & 4 & 6 & \\
\hline Level & & & \\
\hline C3-C4 & 3 & 4 & \\
\hline C4-C5 & 9 & 11 & \\
\hline C5-C6 & 12 & 15 & \\
\hline C6-C7 & 3 & 3 & \\
\hline & & & \\
\hline
\end{tabular}




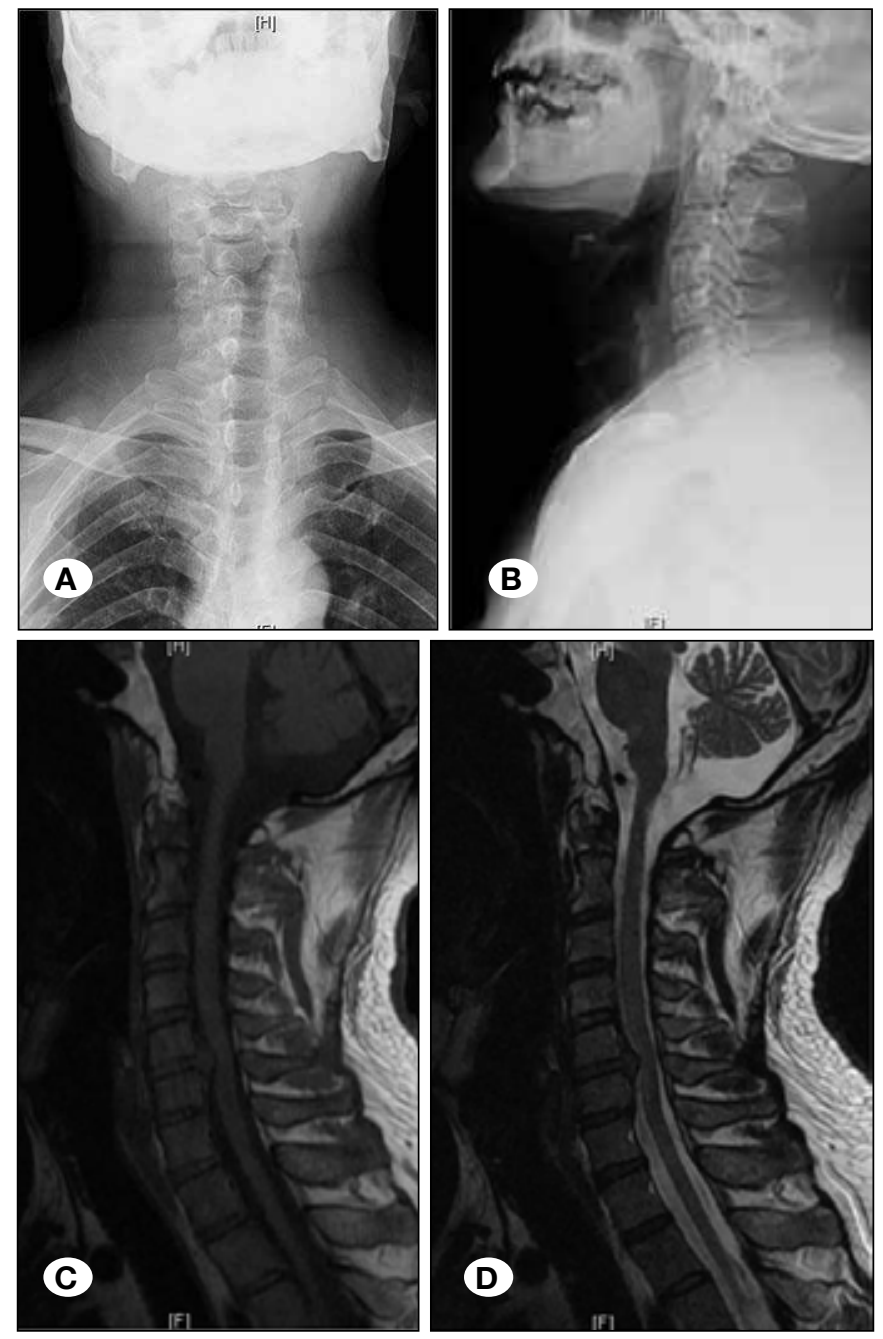

Figure 1: Preoperative anteroposterior (A), lateral (B), T1-weighted (C) and T2-weighted (D) radiographs and magnetic resonance image showing spinal cord compression at C5-C6 level in Zero-P group.
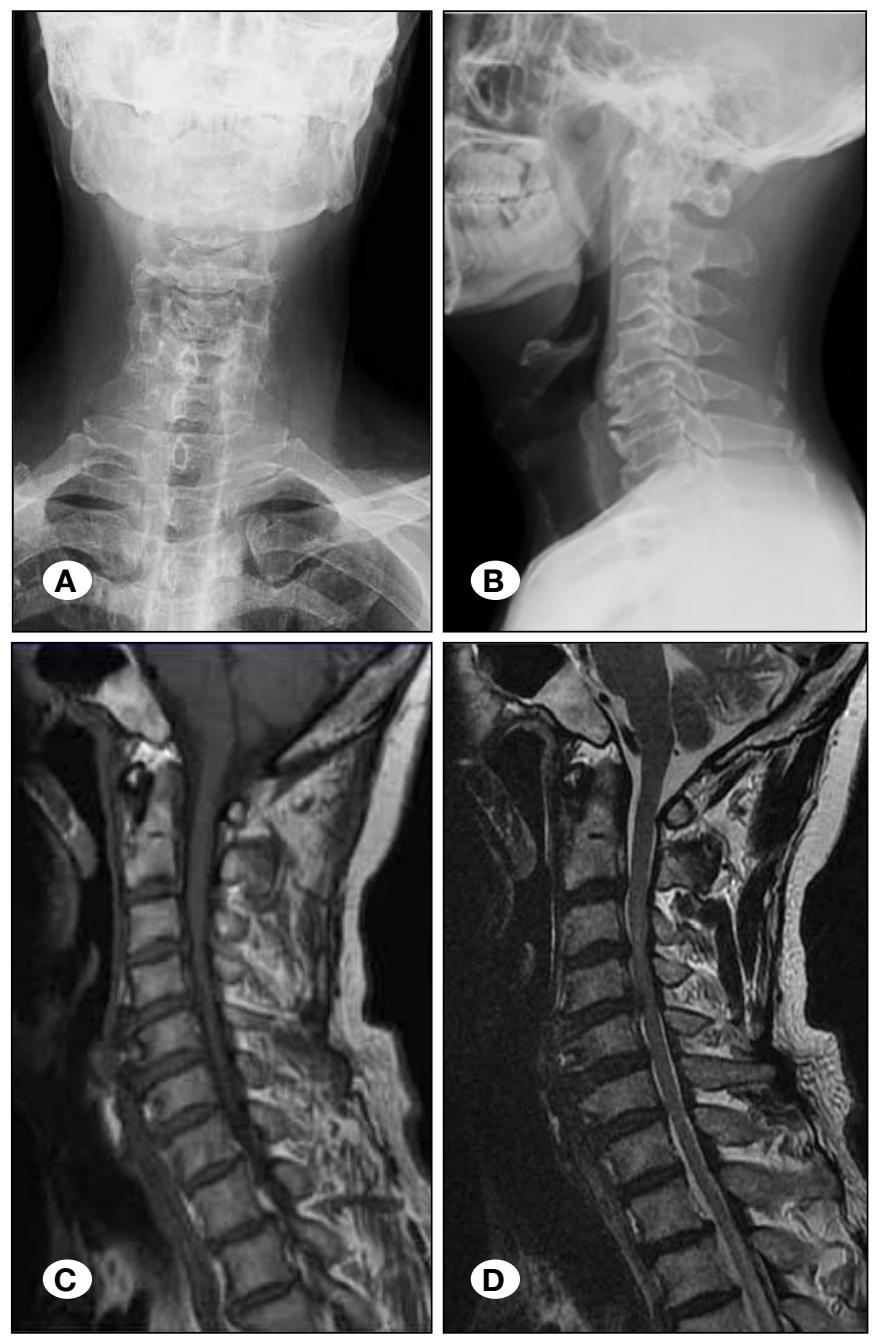

Figure 2: Preoperative anteroposterior (A), lateral (B), T1-weighted (C) and T2-weighted (D) radiographs and magnetic resonance image showing spinal cord compression at C3-C4 and C5-C6 levels in Zero-P group.

Table II: Clinical Follow-up Scores ( $m=$ month)

\begin{tabular}{|c|c|c|c|c|c|c|c|c|}
\hline & \multicolumn{4}{|c|}{ Zero-P group } & \multicolumn{4}{|c|}{ Cage with plate group } \\
\hline & \multirow{2}{*}{ JOA } & \multirow{2}{*}{$\begin{array}{l}\text { ODI } \\
\%\end{array}$} & \multicolumn{2}{|c|}{ SF-36 } & \multirow{2}{*}{ JOA } & \multirow{2}{*}{$\begin{array}{c}\text { ODI } \\
\%\end{array}$} & \multicolumn{2}{|c|}{ SF-36 } \\
\hline & & & PCS & MCS & & & PCS & MCS \\
\hline Pre & $8.5 \pm 1.9$ & $43.7 \pm 13.1$ & $33.6 \pm 4.0$ & $34.4 \pm 4.5$ & $8.3 \pm 1.8$ & $45.1 \pm 10.60$ & $34.1 \pm 4.6$ & $34.7 \pm 4.0$ \\
\hline \multicolumn{9}{|c|}{$\mathrm{FU}$} \\
\hline $3 \mathrm{~m}$ & $12.9 \pm 2.1^{*}$ & $14.2 \pm 9.5^{*}$ & $46.7 \pm 5.1^{*}$ & $44.3 \pm 5.2^{*}$ & $12.5 \pm 3.3^{*}$ & $15.0 \pm 8.5^{*}$ & $45.5 \pm 6.4^{*}$ & $45.1 \pm 7.3^{*}$ \\
\hline $12 \mathrm{~m}$ & $13.2 \pm 3.0^{*}$ & $13.7 \pm 11.6^{*}$ & $47.1 \pm 8.3^{*}$ & $45.0 \pm 5.7^{*}$ & $13.0 \pm 2.4^{*}$ & $14.7 \pm 7.3^{*}$ & $45.8 \pm 5.7^{*}$ & $46.3 \pm 6.5^{*}$ \\
\hline $24 \mathrm{~m}$ & $13.5 \pm 1.9^{*}$ & $13.4 \pm 9.2^{*}$ & $47.4 \pm 7.2^{*}$ & $45.3 \pm 6.4^{*}$ & $13.4 \pm 2.2^{*}$ & $14.2 \pm 7.7^{*}$ & $46.6 \pm 7.0^{*}$ & $46.5 \pm 8.0$ \\
\hline
\end{tabular}

Pre: Pre-operative; JOA: Japanese Orthopaedic Association; NDI: Neck Disability Index; SF-36: Short form-36; FU: Follow up; PCS: Physical component summary; MCS: Mental component summary; "= significant(compared with Pre-operative). 
(4.3\%) complained of dysphagia that persisted beyond 3 months who was also released at the 6 months follow-up. However, 13 of 27 patients (48.1\%) had transient postoperative dysphagia (9 mild, 4 Moderate) and 7 patients (25.9\%)

Table III: Cobb Angle Data ( $\mathrm{m}=\mathrm{month})$

\section{Cobb Angle ( ${ }^{\circ}$ )}

\begin{tabular}{lcc}
\hline & Zero-P group & Cage with plate group \\
\hline Pre-operative & $9.4 \pm 2.3$ & $10.1 \pm 3.5$ \\
\hline $3 \mathrm{FU}$ & \\
\hline $12 \mathrm{~m}$ & $14.1 \pm 4.5^{\star}$ & $15.3 \pm 4.9^{\star}$ \\
\hline $24 \mathrm{~m}$ & $14.4 \pm 5.7^{\star}$ & $15.0 \pm 5.2^{\star}$ \\
\hline
\end{tabular}

*= significant(compared with Pre-operative).
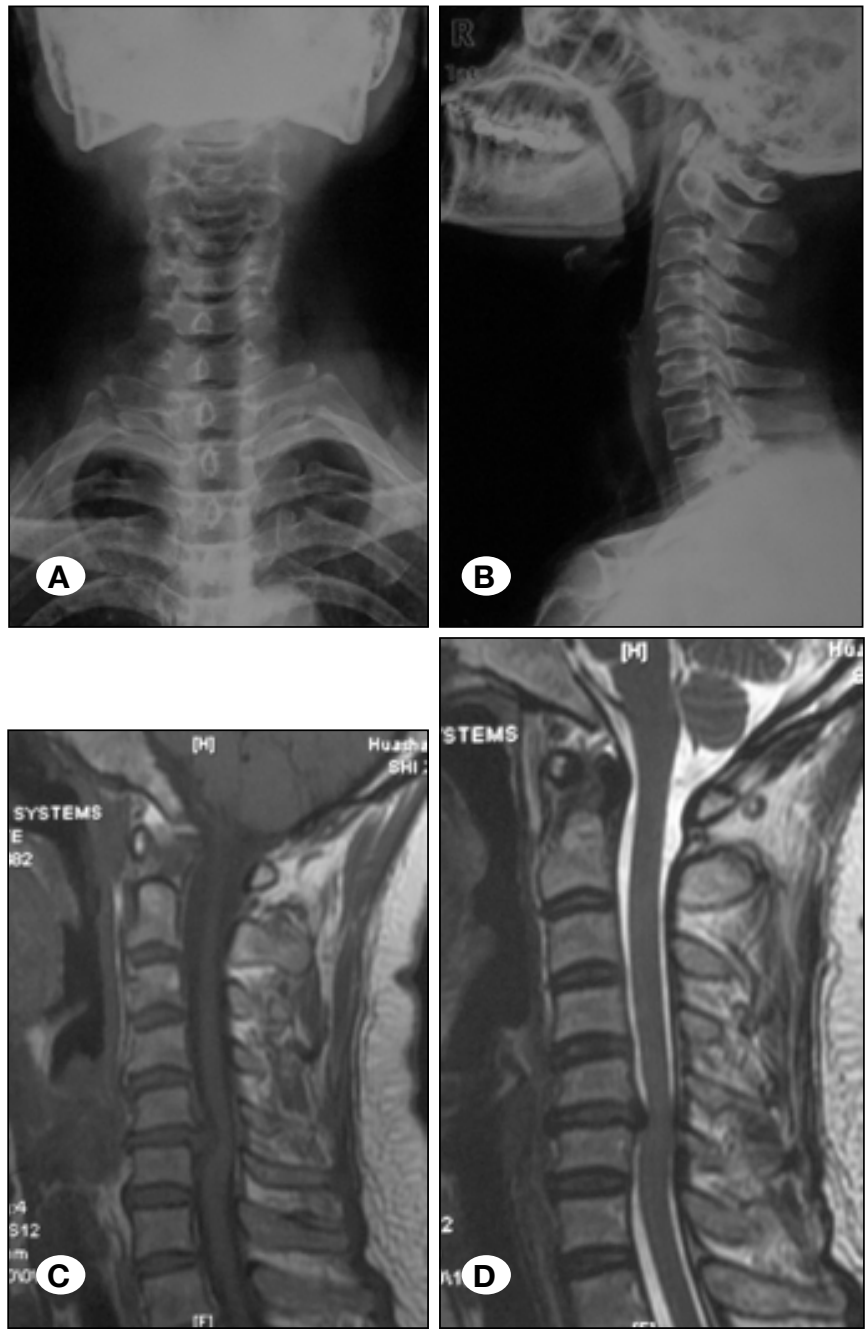

Figure 3: Preoperative anteroposterior (A), lateral (B), T1weighted $(C)$ and T2-weighted (D) radiographs and magnetic resonance image showing spinal cord compression at C5-C6 level in cage with plate group. complained of moderate dysphagia that persisted beyond 3 months in the cage with plate group. As for these 7 patients, 4 were released at the 6 months follow-up, 2 released at the 12 months follow-up and still one female complained of mild dysphagia at final follow-up. Thus, the incidence of dysphagia in the Zero-P group was significantly lower than that in the Cage with plate group $(\mathrm{p}<0.05)$, and the duration was much shorter $(p<0.05)$ (Table IV).

No iatrogenic tracheal, esophageal, or vascular injuries related to the operation occurred. Additional complications included one case of cerebrospinal fluid leakage in each group. Both patients recovered after 5 to 7 days of local pressure and conservative treatment. One patient suffered from a postoperative superficial wound infection in the Zero-P group and the infection resolved after treating with antibiotics. We had two patients with hoarseness of voice who resolved in 5 months in the cage with plate group.
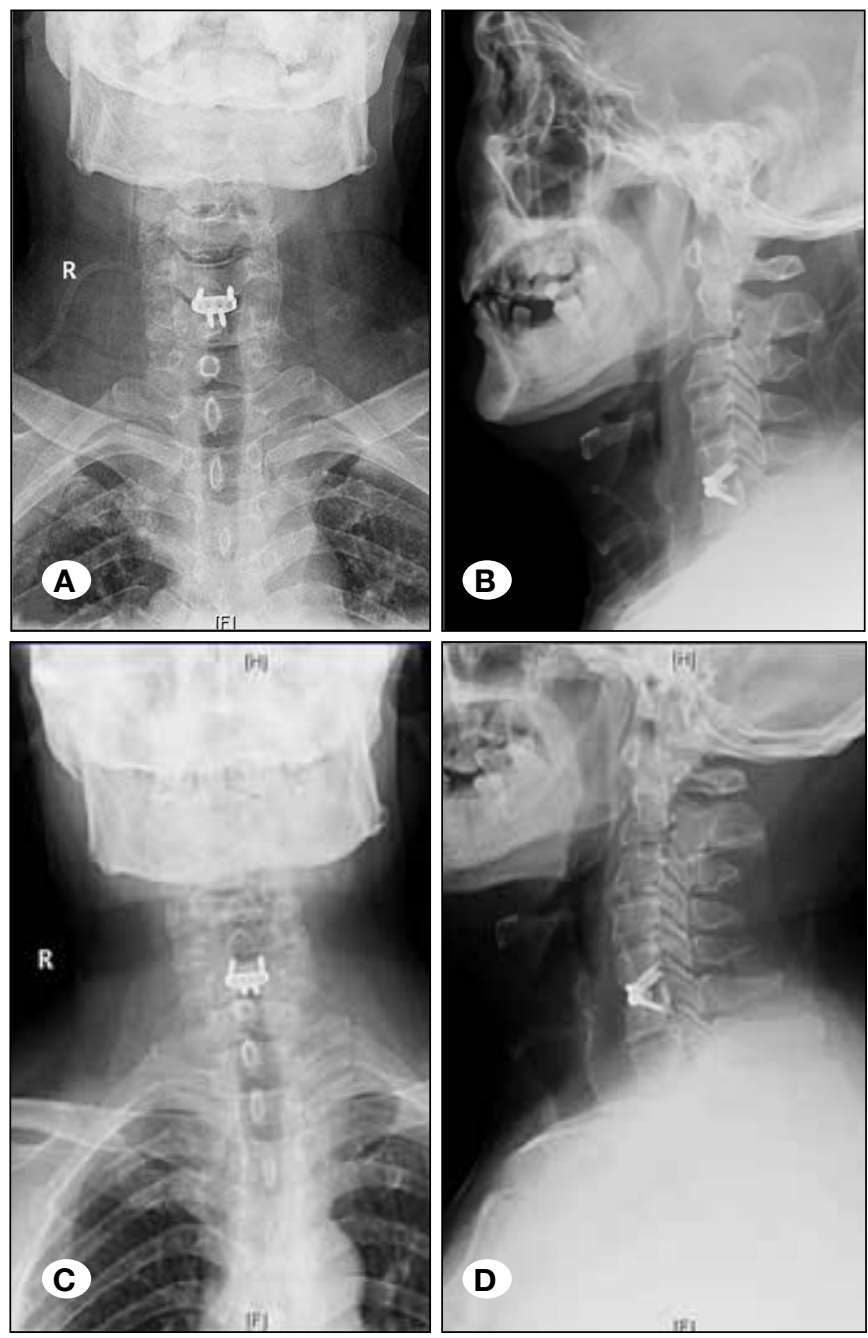

Figure 4: 48 hours postoperative anteroposterior (A), lateral (B) and 6 months postoperative anteroposterior (C), lateral (D) cervical radiographs showing that the cervical lordosis improved and achieved bony fusion at C5-C6 level with Zero-P implant. 
Table IV: Dysphagia Rate and Prevertebral Soft Tissue Thickness of Patients $(\mathrm{d}=$ day, $\mathrm{m}=$ month)

\begin{tabular}{l|cc|cc}
\cline { 2 - 5 } & \multicolumn{2}{c|}{$\begin{array}{c}\text { Dysphagia rate } \\
\%(\text { No.) }\end{array}$} & $\begin{array}{c}\text { Prevertebral soft tissue } \\
\text { thickness (mm) }\end{array}$ \\
\cline { 2 - 5 } & Zero-P & $\begin{array}{c}\text { Cage with } \\
\text { plate }\end{array}$ & Zero-P & $\begin{array}{c}\text { Cage with } \\
\text { plate }\end{array}$ \\
\hline Pre & 0 & 0 & $8.6 \pm 1.1$ & $8.9 \pm 0.9$ \\
\hline \multicolumn{5}{c}{ FU } \\
\hline $2 \mathrm{~d}$ & $21.7(5)$ & $48.1(13)$ & $10.9 \pm 1.1$ & $11.8 \pm 1.1^{*}$ \\
\hline $3 \mathrm{~m}$ & $4.3(1)$ & $25.9(7)^{*}$ & $9.1 \pm 1.1$ & $9.8 \pm 1.0^{*}$ \\
\hline $12 \mathrm{~m}$ & 0 & $7.4(2)$ & $8.8 \pm 0.9$ & $9.4 \pm 1.2$ \\
\hline $24 \mathrm{~m}$ & 0 & $4.3(1)$ & $8.7 \pm 1.1$ & $9.3 \pm 0.9$ \\
\hline
\end{tabular}

Pre: Pre-operative; "= significant(compared with the Zero-P group of the measurement time points during the follow-up period).
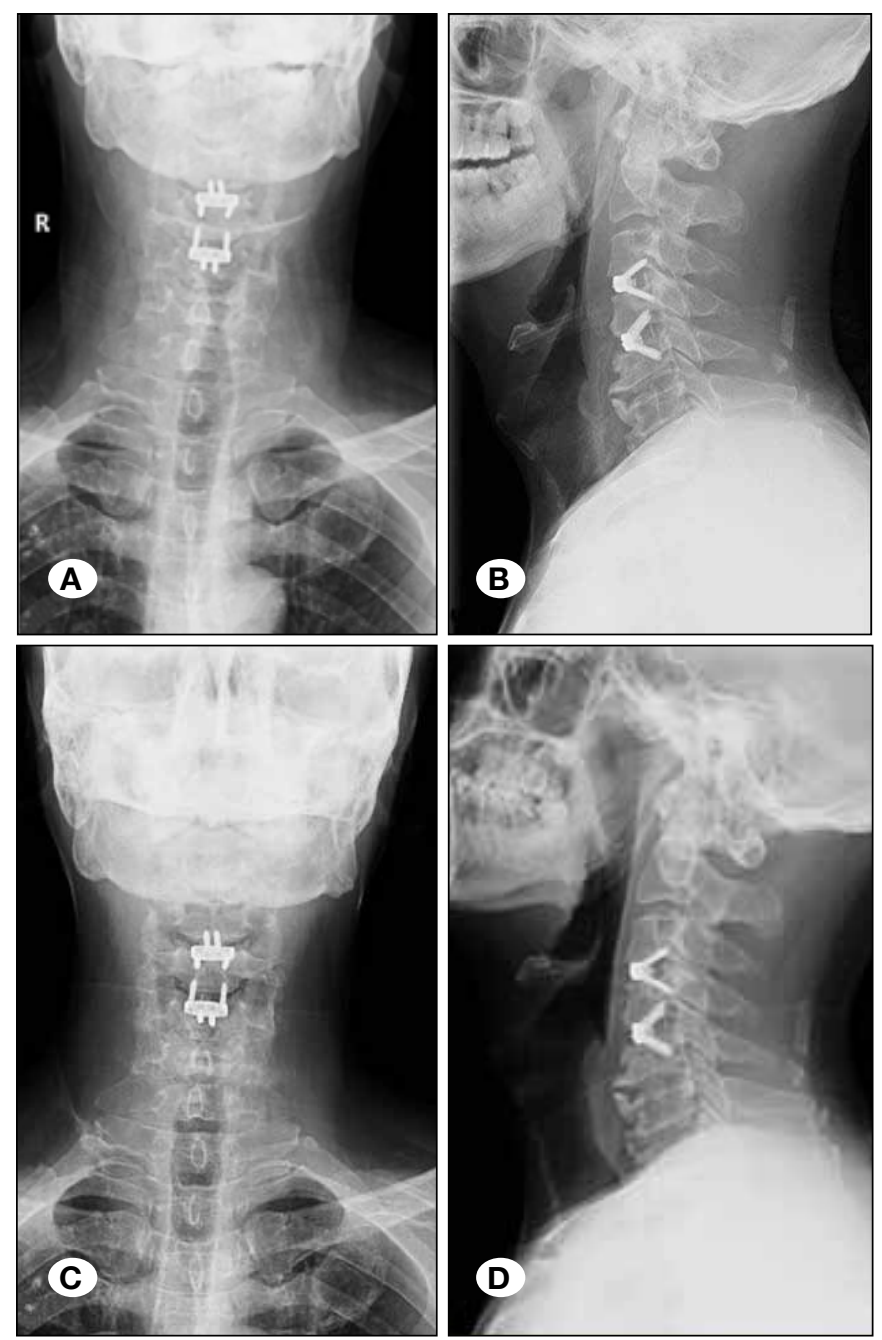

Figure 5: 48 hours postoperative anteroposterior (A), lateral (B) and 6 months postoperative anteroposterior (C), lateral (D) cervical radiographs showing that the cervical lordosis improved and achieved bony fusion at C3-C4 and C5-C6 level with Zero-P implant.

\section{DISCUSSION}

For patients with DCDD where conservative treatment fails, ACDF is a well-established treatment to re-build intervertebral height and cervical lordosis. At present, various cages are widely used for interbody fusion to avoid morbidity at the donor site and complications arising from the use of autologous iliac bone. Surgeons also prefer to add an anterior plate to enhance rigidity of fixation especially in multi-level cases (11, $23,24)$. Although the design of the current anterior plate has been improved over the years, the complications related to the plates are still not rare, and include screw loosening or breakage, plate breakage, and screw pullout with or without migration into the gastrointestinal tract $(15,25)$.

The stand-alone Zero-P device is designed to avoid these complications by combining interbody fusion and supplemental plate fixation into the cage. In our study, the Zero-P device is
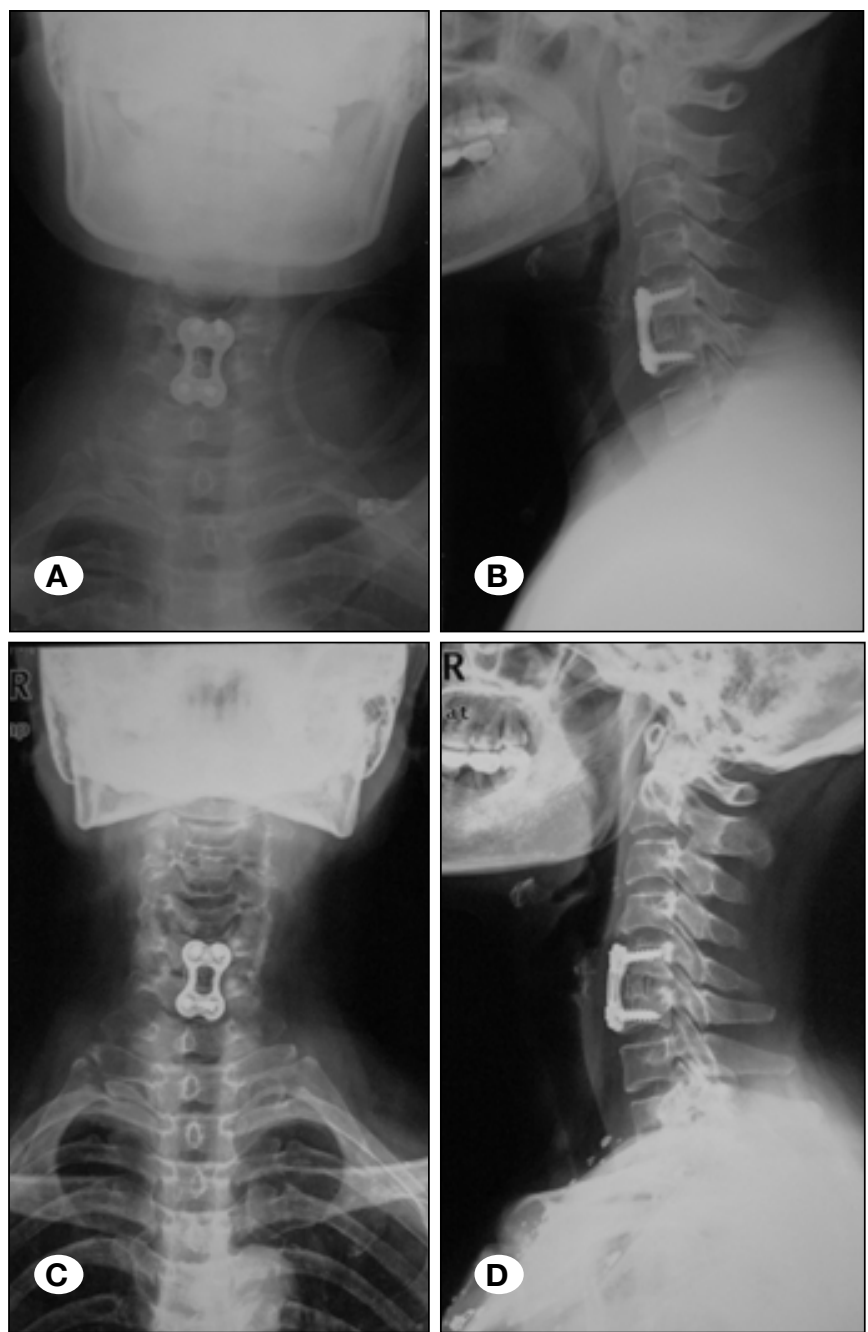

Figure 6: 48 hours postoperative anteroposterior (A), lateral (B) and 6 months postoperative anteroposterior (C), lateral (D) cervical radiographs showing that the cervical lordosis improved and achieved bony fusion at C5-C6 level with cage and plate implant. 
confirmed to provide similar biomechanical stability to that of fusion using an anterior plate and cage and both procedures correct and maintain cervical kyphosis and improve cervical alignment. When referring to the clinical effectiveness measured by JOA and NDI score, the neurological function and symptoms all had significant improvement in the Zero-P group which was similar to the effectiveness of the cage with plate group.

The SF-36 has been widely used in many ACDF and cervical disc prosthesis procedures as an important integral part in evaluating the success of a specific medical treatment (1, 3). Auffinger et al. examined SF-36 in cervical spondylotic myelopathy patients undergoing ACDF after 1 year follow up. The results were SF-36 PCS of $44.22 \pm 9.71$ and MCS of $48.20 \pm 7.54$ (1). In our study as well, values of SF-36 PCS improved from 33.6 to $55.1(P<0.05)$, and MCS improved from 34.4 to $45.3(P<0.05)$ in the Zero-P group. At the same time, when compared with the cage and plate group in our study and other studies, patients that receive a Zero-P device can achieve a better quality of life (1).

The application of the anterior plate is accompanied with various side effects such as soft tissue injury, dysphagia and implant-associated complications. Dysphagia is one of the complications that occur frequently. The dysphagia ( $>3$ months) rate following ACDF with anterior plate has been estimated to range from $12.5 \%$ to $39.1 \%$, while the dysphagia rate (<3 months) ranges from 4.0 to $57.0 \%(2,8,32)$. Severe and persistent dysphagia may lead to some catastrophic event such as not eating or drinking normally and pneumonia (31).

The incidence, severity and duration of dysphagia in our Zero-P group was similar to that of Scholz and Hofstetter $(6,19)$ who used Zero-P implants with lower incidence of transient and chronic dysphagia postoperatively and was much less than that in our cage with plate group and other investigators (8, 20,32 ). A relationship between postoperative swelling of the prevertebral soft tissue and postoperative dysphagia has been reported $(22,26)$. Increased thickness of the prevertebral soft tissue is also considered a risk factor of dysphagia. The mean thickness of the prevertebral soft tissue was less in the Zero-P group in the first 3 months and resulted in lower incidence and duration of dysphagia.

The presence of the plate itself in front of the anterior cervical and its irritation of the esophagus is considered to be a possible cause of postoperative dysphagia (27). It has been shown that plates with smoother surface can reduce the chance of irritating or impinging the esophagus and the occurrence of dysphagia $(12,32)$. The significantly lower incidence of postoperative dysphagia in patients after cervical arthroplasty as compared with those treated with cage and plate also confirmed this theory (13). The Zero-P device can be inserted directly into the disc space and avoids direct contact with the soft tissue in front of the cervical to prevent mechanical irritation of the esophagus. This may also explain the lower thickness of the prevertebral soft tissue in our Zero-P group.
Another possible mechanism for high postoperative dysphagia rate following ACDF with plate may be the additional traction and more time needed to control the angle of the screws and length of the plate to place the plate correctly $(11,14,15)$. Increased pressure on the esophagus during implantation of the plate and direct stimulus of esophagus may contribute to the dysphagia $(5,31)$. The Zero-P device can be inserted into the disc space directly and the screws can be easily installed with the help of the trajectories. Thus smaller operative field and fewer steps are needed to place the Zero-P with only a little part of the upper and lower vertebrae of the responsible segment exposed, and the one-step locking mechanism with simple insertion of the cage and tightening of the screws (16). The less esophagus retraction extent and less intraoperative retraction time to install the Zero-P device may also contribute to the lower rate of dysphagia (17).

The use of the Zero-P device still has some disadvantage especially in the upper and lower cervical spine (19). It was easy to use the implant in the levels C4/C5, C5/C6 and C6/C7. Below and above, especially in patients with a short neck or high sternum, the lower screws of $\mathrm{C} 3 / 4$ and the upper screws of the C6/7 segment are hard to introduce at an optimal angle, even with the help of angled instruments. A wider skin incision and increased retraction may be needed.

\section{CONCLUSION}

According to our study, the primary clinical and radiographic efficacy of Zero-P used in ACDF is satisfactory in a relatively large number of patients over a minimum 2-year follow-up and can be used as a valid alternative to anterior cervical plating. The incidence of postoperative dysphagia was lower and the duration was shorter in the Zero-p group compared to the cage with plate group. More patients and longer follow-up periods are needed for further confirmation of the results we have obtained in this study.

\section{- REFERENCES}

1. Auffinger BM, Lall RR, Dahdaleh NS, Wong AP, Lam SK, Koski T, Fessler RG, Smith ZA: Measuring surgical outcomes in cervical spondylotic myelopathy patients undergoing anterior cervical discectomy and fusion: Assessment of minimum clinically important difference. PLoS One 8:e67408, 2013

2. Bazaz R, Lee MJ, Yoo JU: Incidence of dysphagia after anterior cervical spine surgery: A prospective study. Spine (Phila Pa 1976) 27:2453-2458, 2002

3. Cheng L, Nie L, Li M, Huo Y, Pan X: Superiority of the Bryan((R)) disc prosthesis for cervical myelopathy: A randomized study with 3-year follow-up. Clin Orthop Relat Res 469:3408-3414, 2011

4. Chin KR, Eiszner JR, Adams Jr SB: Role of plate thickness as a cause of dysphagia after anterior cervical. Spine 32:25852590, 2007

5. Heese O, Fritzsche E, Heiland M, Westphal M, Papavero L: Intraoperative measurement of pharynx/esophagus retraction during anterior cervical surgery. Part II: Perfusion. Eur Spine J 15:1839-1843, 2006 
6. Hofstetter CC, Kesavabhotla K, Boockvar JA: Zero-profile anchored spacer reduces rate of dysphagia compared to ACDF with anterior plating. J Spinal Disord Tech 28(5):E284290,2015

7. lampreechakul P, Srisawat C, Tirakotai W: Stand-alone cervical polyetheretherketone (PEEK) cage (cervios) for single to two-level degenerative disc disease. J Med Assoc Thai 94:185-192, 2011

8. Kalb S, Reis MT, Cowperthwaite MC, Fox DJ, Lefevre R, Theodore N, Papadopoulos SM, Sonntag VK: Dysphagia after anterior cervical spine surgery: Incidence and risk factors. World Neurosurg 77:183-187, 2012

9. Kim HJ, Kelly MP, Ely CG, Dettori JR, Riew KD: The risk of adjacent-level ossification development after surgery in the cervical spine: Are there factors that affect the risk? A systematic review. Spine (Phila Pa 1976) 37:S65-74, 2012

10. Korinth MC: Treatment of cervical degenerative disc disease - current status and trends. Zentralbl Neurochir 69:113-124, 2008

11. Lee $\mathrm{CH}$, Hyun SJ, Kim MJ, Yeom JS, Kim WH, Kim KJ, Jahng TA, Kim HJ, Yoon SH: Comparative analysis of 3 different construct systems for single-level anterior cervical discectomy and fusion: Stand-alone cage, iliac graft plus plate augmentation, and cage plus plating. J Spinal Disord Tech 26:112-118, 2013

12. Lee MJ, Bazaz R, Furey CG, Yoo J: Risk factors for dysphagia after anterior cervical spine surgery: A two-year prospective cohort study. Spine J 7:141-147, 2007

13. McAfee PC, Cappuccino A, Cunningham BW, Devine JG, Phillips FM, Regan JJ, Albert TJ, Ahrens JE: Lower incidence of dysphagia with cervical arthroplasty compared with ACDF in a prospective randomized clinical trial. J Spinal Disord Tech 23:1-8, 2010

14. Miao J, Shen Y, Kuang Y, Yang L, Wang X, Chen Y, Chen D: Early follow-up outcomes of a new zero-profile implant used in anterior cervical discectomy and fusion. Spinal Disord Tech 26:E193-E197, 2013

15. Pitzen TR, Chrobok J, Stulik J, Ruffing S, Drumm J, Sova L, Kucera R, Vyskocil T, Steudel WI: Implant complications, fusion, loss of lordosis, and outcome after anterior cervical plating with dynamic or rigid plates: Two-year results of a multi-centric, randomized, controlled study. Spine (Phila $\mathrm{Pa}$ 1976) 34:641-646, 2009

16. Qi M, Chen H, Liu Y, Zhang Y, Liang L, Yuan W: The use of a zero-profile device compared with an anterior plate and cage in the treatment of patients with symptomatic cervical spondylosis A preliminary clinical investigation. Bone Joint $J$ 95:543-547, 2013

17. Rihn JA, Kane J, Albert TJ, Vaccaro AR, Hilibrand AS: What is the incidence and severity of dysphagia after anterior cervical surgery? Clin Orthop Relat Res 469:658-665, 2011

18. Scholz M, Reyes PM, Schleicher P, Sawa AG, Baek S, Kandziora F, Marciano FF, Crawford NR: A new stand-alone cervical anterior interbody fusion device: Biomechanical comparison with established anterior cervical fixation devices. Spine (Phila Pa 1976) 34:156-160, 2009
19. Scholz M, Schnake KJ, Pingel A, Hoffmann R, Kandziora F: A new zero-profile implant for stand-alone anterior cervical interbody fusion. Clin Orthop Relat Res 469:666-673, 2011

20. Siska PA, Ponnappan RK, Hohl JB, Lee JY, Kang JD, Donaldson WF, 3rd: Dysphagia after anterior cervical spine surgery: A prospective study using the swallowing-quality of life questionnaire and analysis of patient comorbidities. Spine (Phila Pa 1976) 36:1387-1391, 2011

21. Smith GW, Robinson RA: The treatment of certain cervicalspine disorders by anterior removal of the intervertebral disc and interbody fusion. J Bone Joint Surg Am 40-A:607-624, 1958

22. Song KJ, Choi BW, Kim HY, Jeon TS, Chang H: Efficacy of postoperative radiograph for evaluating the prevertebral soft tissue swelling after anterior cervical discectomy and fusion. Clin Orthop Surg 4:77-82, 2012

23. Song KJ, Taghavi CE, Hsu MS, Lee KB, Kim GH, Song JH: Plate augmentation in anterior cervical discectomy and fusion with cage for degenerative cervical spinal disorders. Eur Spine J 19:1677-1683, 2010

24. Song KJ, Taghavi CE, Lee KB, Song JH, Eun JP: The efficacy of plate construct augmentation versus cage alone in anterior cervical fusion. Spine (Phila Pa 1976) 34:2886-2892, 2009

25. Stulik J, Pitzen TR, Chrobok J, Ruffing S, Drumm J, Sova L, Kucera R, Vyskocil T, Steudel WI: Fusion and failure following anterior cervical plating with dynamic or rigid plates: 6-months results of a multi-centric, prospective, randomized, controlled study. Eur Spine J 16:1689-1694, 2007

26. Suk KS, Kim KT, Lee SH, Park SW: Prevertebral soft tissue swelling after anterior cervical discectomy and fusion with plate fixation. Int Orthop 30:290-294, 2006

27. Vanek P, Bradac O, Delacy P, Lacman J, Benes V: Anterior interbody fusion of the cervical spine with zero-p spacer: Prospective comparative study-clinical and radiological results at a minimum 2 years after surgery. Spine (Phila $\mathrm{Pa}$ 1976) 38:E792-797, 2013

28. Wang CS, Chang JH, Chang TS, Chen HY, Cheng CW: Loading effects of anterior cervical spine fusion on adjacent segments. Kaohsiung J Med Sci 28:586-594, 2012

29. Yamagata T, Takami T, Uda T, Ikeda H, Nagata T, Sakamoto $\mathrm{S}$, Tsuyuguchi N, Ohata K: Outcomes of contemporary use of rectangular titanium stand-alone cages in anterior cervical discectomy and fusion: Cage subsidence and cervical alignment. J Clin Neurosci 19:1673-1678, 2012

30. Yang L, Gu Y, Liang L, Gao R, Shi S, Shi J, Yuan W: Stand-alone anchored spacer versus anterior plate for multilevel anterior cervical diskectomy and fusion. Orthopedics 35:e1503-1510, 2012

31. Yue W-M, Brodner W, Highland TR: Persistent swallowing and voice problems after anterior cervical discectomy and fusion with allograft and plating: A 5-to 11-year follow-up study. Eur Spine J 14:677-682, 2005

32. Zeng JH, Zhong ZM, Chen JT: Early dysphagia complicating anterior cervical spine surgery: Incidence and risk factors. Arch Orthop Trauma Surg 133: 1067-1071, 2013 